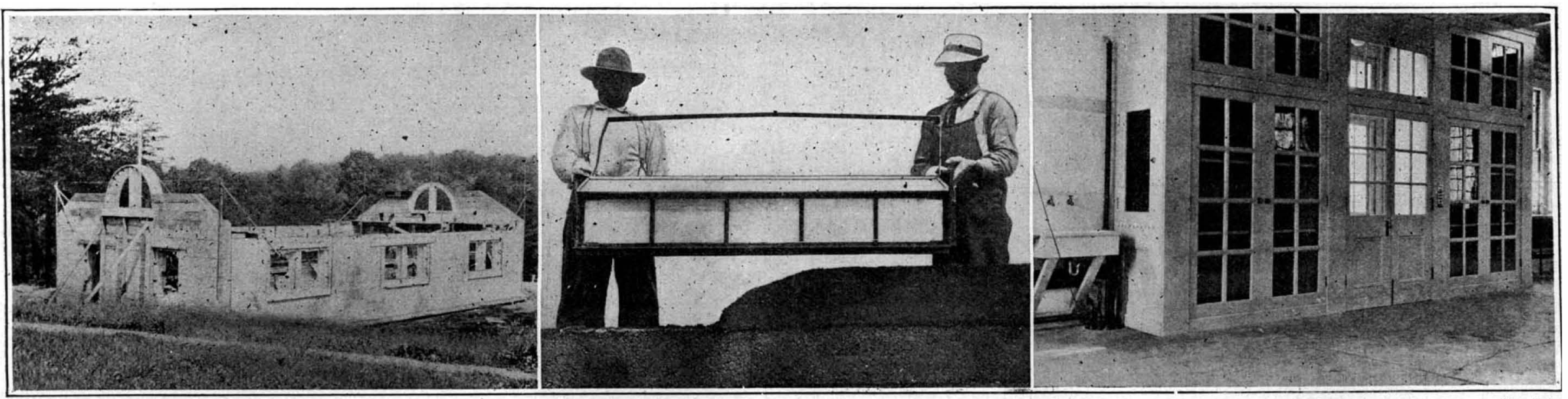

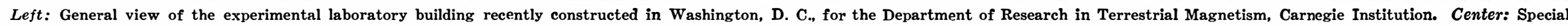
mould employed in forming the walls of the building. Right: Double doors used in interior of laboratory building and some of the non-magnetic piping

Details of the non-magnetic experimental laboratory building constructed at Washington, D. C., for research in terrestrial magnetism

Piloting the Ship with the Ears By George Gaulois

THE day is not far distant when sailors will no longer fear fog and the darkness of the night. It will no longer be necessary to lose much valuable time at the entrance to a harbor, waiting for favorable conditions as is the case with our present method of piloting ships. The radio cable, developed during the world war for guiding friendly ships through thic mine fields and through narrow waterways at night, has been found to mean more in peace time than it could ever mean in military operations. This device, which is now being introduced in several leading countries, is almost certain to reduce the dangers of fog and darkness to a minimum.

Briefly, the principle of the radio cable, as it is called, is to employ a cable through which flows a 500 cycle alternating current. Ships intending to use the cable while passing in and out of waterways are provided with a pair of coils which intercept the electromagnetic waves emanating from the cable. By notin the relative strength of the waves reaching each coil, it is possible for the ship's navigator to determine when he is approaching the cable, on which side it is, and, with the sound in the head 'phones equal for both coils, when he is riding astride the relatively rect course. In certain installations two cables are laid, each either carrying a current of different frequency so as to cause a difference in the tone of the signals, of the same frequency but with certain interruptions of a fixed kind so as to represent readily identified signals. In either event the navigator can determine which is the outgoing and which is the incoming cable, and in that manner select the proper on and thus avoid the danger of collision with a vessel and thus avoid the danger of coll

On October 6th last the United States Navy conducted an interesting public test of the sixteen-mile radio cable laid from near the Ambrose Channel Lightship to Fort Lafayette in the Narrows, or in the main waterway approaching the port of New York. With his pilot windows covered with heavy canvas, as shown in one of the accompanying illustrations, Commander Norton of the destroyer "Semmes" piloted his vessel alon the cable and guided the "Semmes" by "listening in" and steering to port or starboard as the volume of sound indicated his position.

It was the good fortune of the Scientific American It was the good fortune of the SCIENTIFIC AMERICAN
to obtain details of the radio cable installation in New York Harbor some time before the present test. In York Harbor some time before the present test. Indeed, complete details of this novel installation are to
be found on page 195 of the August 28, 1920, issue. Readers who missed that number are referred to it for a complete drawing of the cable and the technical details.

In the case of the "Semmes" the installation consisted of two large receiving coils mounted above the water line on either side of the steel hull. These coils, it will be noted from another one of the accompanying illus trations, resmo ane trations, resemble nothing so much as large but empty black frames. These coils are each connected with a
two-stage vacuum-tube amplifier, which amplifies the two-stage vacuum-tube amplifier, which amplifies the weak currents induced from the radio cable, some fou hundred times. The current, being of an audible frequency, is led directly to a pair of head 'phones. In the case of this test the cable current was interrupted so as to spell "N A V Y" in the usual telegraph code, and these signals registered in the head 'phones in the form of soft but positive clicks. A simple switch makes it possible for the navigator to listen in on eithe coil and so determine the relative force of the electromagnetic waves reaching each coil.

It is interesting to note that the radio cable has been developed by Earl C. Hanson, a young Californian, whose radio work dates back to the early days of amateur wireless on the Pacific coast.

\section{Rust Preventives} W HENEVER machinery is shipped or stored the problem. It has been an attractive problem to chemists and the market now affords several compounds designed to protect the metal surface, to cling tenaciously to it and yet be easily removed under certain cond tions. One of the compounds not only prevents the for mation of new oxide or rust, but makes preliminary cleaning unnecessary, takes care of any moisture that may be present upon the surface, and is even said to remove any traces of preliminary rust which may be present when the compound is applied.

\section{A Magnetic-Proof House for the Workers} By Harry A. Mount

BUILDING of unique construction, in which not an A ounce of steel or iron is used, has recently been completed in Washington for use as an experimental labratory for the Department of Research in Terrestrial Magnetism, Carnegie Institution.

The outer walls are of double concrete construction, with $21 / 2$ inches of dead air space between. The reinforcement is brass rods, tied together with brass tie wires.

The building requirements for the research work contemplated were $(a)$ unusual rigidity and strength, (b) non-magnetic construction, and (c) insulation gainst sudden external temperature changes.

After careful consideration the double-wall monolithic construction was adopted. The walls were built up with a Van Guilder machine. This consists of four steel plates held parallel with proper braces. The walls are built up tier by tier, a rather dry mixture of concrete being tamped in the mold, and the machine being moved on along the wall without waiting for the concrete to dry. A stucco finish is placed directly on the outside wall when completed and plaster is placed directly on the inside wall. The sill courses about the building and under the windows and the colums at the entrance of the building are of artificial stone with a
fine granite and mica surface, and were all cast in place with the walls.

Further insulation against sudden temperature changes is provided by double windows and double doors and by a double ceiling of plaster-board, enclosing a dead air space of 10 inches between.

Because of the unusual requirements and specifications, particularly those for non-magnetic construction, it was not possible to secure a contract for the work, which had, therefore, to be undertaken by the Department. It was impossible, even, to secure bids for the special mill-work required, all of which had to be done in their own shop. The cost of construction, despite the increased expense necessary, was about 30 cents per cubic foot of volume enclosed, comparing very favorably with prevailing rates for ordinary lumber construction.

The equipment of the building, other than the special (Continued on page 438)

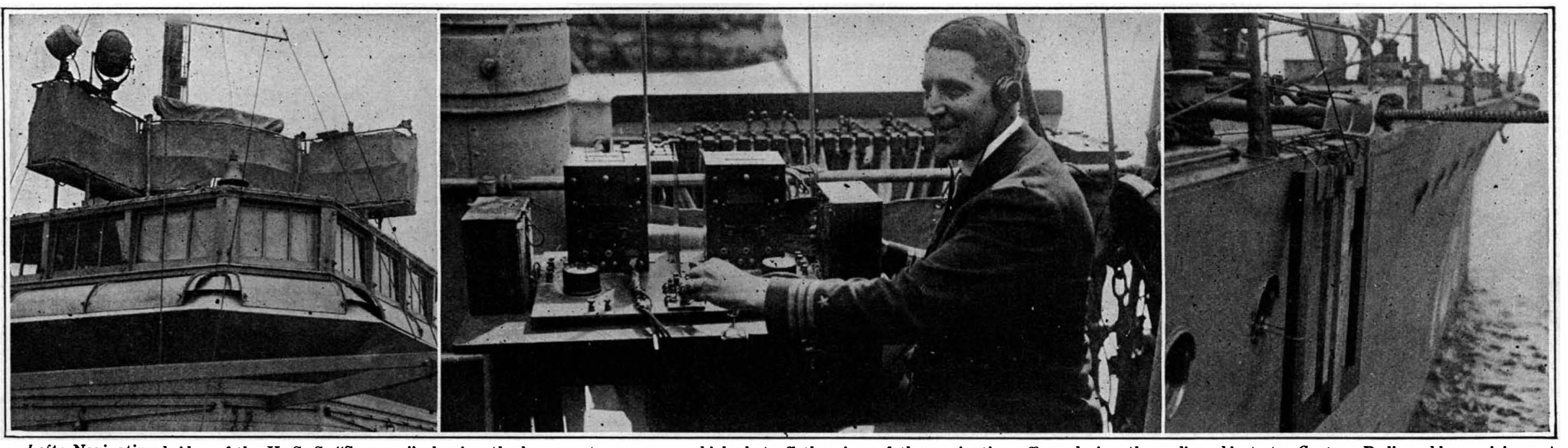

Left: Navigating bridge of the U. S. S. "Semmes," showing the heavy canvas screens which shut of the view of the navigating officer during the radio cable test. Center: Radio cable receiving set aboard the "Semmes," with two two-stage amplifiers, sensitive electric meters, switch for connecting to either coil, and pair of head 'phones very much in evidence. Right: One of the coils mounted on one side of the steel hull 